\title{
Hyperpolarized in vivo pH imaging reveals grade-dependent acidification in prostate cancer
}

\author{
David E. Korenchan ${ }^{1}$, Robert Bok ${ }^{1}$, Renuka Sriram ${ }^{1}$, Kristina Liu ${ }^{5}$, Romelyn Delos \\ Santos ${ }^{1}$, Hecong Qin ${ }^{1}$, Iryna Lobach ${ }^{2}$, Natalie Korn ${ }^{1}$, David M. Wilson ${ }^{1}$, John \\ Kurhanewicz ${ }^{1,3,4}$ and Robert R. Flavell ${ }^{1,3, *}$ \\ ${ }^{1}$ Department of Radiology and Biomedical Imaging, University of California, San Francisco, CA, USA \\ ${ }^{2}$ Department of Epidemiology and Biostatistics, University of California, San Francisco, CA, USA \\ ${ }^{3}$ Department of Pharmaceutical Chemistry, University of California, San Francisco, CA, USA \\ ${ }^{4}$ Department of Urology, University of California, San Francisco, CA, USA \\ ${ }^{5}$ Department of Physical Chemistry, Technical University of Munich, Munich, Germany \\ Correspondence to: Robert R. Flavell, email: Robert.Flavell@ucsf.edu \\ Keywords: prostate cancer; extracellular pH; hyperpolarization; MRl; metabolism \\ Received: August 01, $2019 \quad$ Accepted: September 10,2019 Published: October 22, 2019 \\ Copyright: Korenchan et al. This is an open-access article distributed under the terms of the Creative Commons Attribution License \\ 3.0 (CC BY 3.0), which permits unrestricted use, distribution, and reproduction in any medium, provided the original author and \\ source are credited.
}

\section{ABSTRACT}

There is an unmet clinical need for new and robust imaging biomarkers to distinguish indolent from aggressive prostate cancer. Hallmarks of aggressive tumors such as a decrease in extracellular $\mathrm{pH}\left(\mathrm{pH}_{\mathrm{e}}\right)$ can potentially be used to identify aggressive phenotypes. In this study, we employ an optimized, high signalto-noise ratio hyperpolarized (HP) ${ }^{13} \mathrm{C} \mathrm{pH}_{\mathrm{e}}$ imaging method to discriminate between indolent and aggressive disease in a murine model of prostate cancer. Transgenic adenocarcinoma of the mouse prostate (TRAMP) mice underwent a multiparametric MR imaging exam, including $\mathrm{HP}\left[{ }^{13} \mathrm{C}\right]$ bicarbonate $\mathrm{MRI}$ for $\mathrm{pH}_{\mathrm{e}^{\prime}}$ with ${ }^{1} \mathrm{H}$ apparent diffusion coefficient (ADC) mapping and HP $\left[1^{-13} \mathrm{C}\right]$ pyruvate MRI to study lactate metabolism. Tumor tissue was excised for histological staining and qRT-PCR to quantify mRNA expression for relevant glycolytic enzymes and transporters. We observed good separation in $\mathrm{pH}_{\mathrm{e}}$ between low- and high-grade tumor regions, with high-grade tumors demonstrating a lower $\mathrm{pH}_{\mathrm{e}}$. The $\mathrm{pH}_{\mathrm{e}}$ also correlated strongly with monocarboxylate transporter Mct4 gene expression across all tumors, suggesting that lactate export via MCT4 is associated with acidification in this model. Our results implicate extracellular acidification as an indicator of indolent-to-aggressive transition in prostate cancer and suggest feasibility of $\mathrm{HP} \mathrm{pH}_{\mathrm{e}}$ imaging to detect high-grade, clinically significant disease in men as part of a multiparametric MRI examination.

\section{INTRODUCTION}

Current clinical management of prostate cancer is lacking in the ability to confidently distinguish indolent from aggressive tumors. As of 2019, prostate cancer had the highest incidence rate, $20 \%$ of all new cases, and the second-highest mortality rate, responsible for $10 \%$ of all cancer deaths [1]. The majority of prostate cancer diagnoses, however, are tumors that do not require treatment [2]. For patients with prostate tumors that are likely indolent, typically having less than $0.5 \mathrm{cc}$ of volume and a Gleason grade below $3+3$, active surveillance represents a clinical standard for detecting indolent-to-aggressive transition [3]. Imaging, and in particular multiparametric ${ }^{1} \mathrm{H}$ MRI, plays a prominent role in active surveillance because of its ability to localize aggressive focal lesions within the prostate for focal therapy [4]. Nevertheless, prostate MRI still suffers from a high incidence of both false positive [5] and false negative [6] events, requiring other biomarkers and associated imaging techniques for delineation of focal lesions. 
Prostate cancer demonstrates prominent metabolic alterations from native tissue that may be detectable via molecular imaging. The glycolytic shift of prostate cancer cells from citrate secretion to lactate production, measurable in biological samples or in living systems using magnetic resonance (MR) techniques $[7,8]$, is one parameter that has demonstrated considerable potential for indicating cancer aggressiveness. Increased production of lactate can be measured with hyperpolarized (HP) ${ }^{13} \mathrm{C}$ $\mathrm{MR}$, which relies upon dramatic MR signal enhancement provided by dynamic nuclear polarization (DNP) [9]. This technique has been translated into clinical research studies, and the increased production of lactate can be directly visualized through imaging following administration of $\left[1-{ }^{13} \mathrm{C}\right]$ pyruvate [10]. Furthermore, multiple biological parameters can be simultaneously measured in the same imaging session with this technique [11]. Other cellular changes associated with this metabolic shift have also been identified. In particular, increased lactic acid export via monocarboxylate transporter 4 (MCT4) overexpression has been observed in high-grade renal cell carcinoma cell lines [12] and patient-derived tissue slices [13]. The MCT4 transporter is overexpressed in aggressive murine prostate cancer [14] and patient-derived tissue slices [15]. Although this increase in lactic acid efflux can be measured in vivo using diffusion-weighted imaging [16], the inherent changes in cellularity with tumor grade in prostate cancer obfuscate the changes in the apparent diffusion coefficient and reduce the dynamic range between intracellular and extracellular compartments.

Extracellular acidification, in part a consequence of this altered metabolism, represents a possible biomarker for the detection of aggressive prostate cancer [17]. Solid tumors typically have high metabolic activity and rapid cell proliferation; consequently, they develop an acidic interstitial microenvironment ( $\mathrm{pH}$ 6.5-7.2). Acidic extracellular $\mathrm{pH}$ is associated with local invasion and metastasis in a variety of cancers, including melanoma, breast and colon cancer [18-21]. Evaluation of prostate cancer models has demonstrated that these tumors have an acidic extracellular $\mathrm{pH}[11,22]$. Moreover, treatment with $\mathrm{pH}$-increasing therapies such as sodium bicarbonate inhibits tumor formation in prostate cancer models [23]. A variety of methods have been developed for imaging $\mathrm{pH}$ in vivo [24], including hyperpolarized ${ }^{13} \mathrm{C}$ magnetic resonance techniques [22, 25-28]. Recently, we have developed a method for high signal-to-noise ratio (SNR) imaging of extracellular $\mathrm{pH}$ using a precursor molecule, $\left[1-{ }^{13} \mathrm{C}\right]$ glycerol carbonate, which can be converted to $\left[{ }^{13} \mathrm{C}\right]$ bicarbonate, administered to an animal, and rapidly imaged to generate maps of tumor $\mathrm{pH}_{\mathrm{e}}$ [22]. Importantly, this method is anticipated to have a low barrier to entry into the clinic, considering the low toxicity of sodium bicarbonate.

We hypothesized that alterations in tumor $\mathrm{pH}_{\mathrm{e}}$, metabolism, and cellularity could represent imaging biomarkers of low- to high-grade cancer transition in prostate cancer. In order to test this hypothesis, we applied our recently-developed $\mathrm{HP}_{\mathrm{pH}}$ imaging method, in combination with $\left[1-{ }^{13} \mathrm{C}\right]$ pyruvate imaging and ${ }^{1} \mathrm{H}$ diffusion-weighted imaging, in a cohort of transgenic adenocarcinoma of the mouse prostate (TRAMP) mice [29]. The imaging findings were compared with pathologic outcome and enzyme/transporter gene expression measurements.

\section{RESULTS}

\section{${ }^{1} \mathrm{H}$ MR imaging and mouse model}

We developed and implemented a new multiparametric MR protocol to study extracellular acidification, glycolytic metabolism, and tumor cellularity in a single imaging exam (Figure 1). Hyperpolarization and rapid hydrolysis of $\left[1-{ }^{13} \mathrm{C}\right] 1,2$-glycerol carbonate generated a solution of highly polarized and concentrated $\left[{ }^{13} \mathrm{C}\right]$ bicarbonate along with an equimolar concentration of glycerol, as previously reported by our group [22]. Notably, the percent polarization and concentration of the $\left[{ }^{13} \mathrm{C}\right]$ bicarbonate $(19 \%$ and $100 \mathrm{mM})$ was similar to that of $\left[1-{ }^{13} \mathrm{C}\right]$ pyruvate $(18 \%$ and $80 \mathrm{mM})$, when backcalculated to the time of dissolution. The $\left[{ }^{13} \mathrm{C}\right]$ bicarbonate signal enabled $\mathrm{pH}_{\mathrm{e}}$ imaging in mouse prostate tumors with sufficient spatial resolution to capture tumor heterogeneity. This was combined with imaging of hyperpolarized $\left[1-{ }^{13} \mathrm{C}\right]$ lactate produced from $\left[1-{ }^{13} \mathrm{C}\right]$ pyruvate and ${ }^{1} \mathrm{H}$ diffusionweighted imaging in order to study glycolysis, acidosis, and tumor cellularity in a single imaging exam.

We chose to use the genetically engineered TRAMP mouse model in order to study metabolic, morphologic, and microenvironmental changes. This mouse model is known to recapitulate the phenotype of human prostate cancer, particularly with regards to lactate metabolism $[8,14,30]$, and progresses through low- and high-grade stages analogous to human prostate cancer [31]. We performed HP and conventional MR imaging on a total of 10 TRAMP mice. Anatomical ${ }^{1} \mathrm{H}$ images as well as ${ }^{1} \mathrm{H}$ apparent diffusion coefficient (ADC) maps revealed considerable inter- and intra-tumoral heterogeneity (Figure 2A, 2B). Eight of the 10 mice displayed lesions that could be grossly classified histologically as either "low-grade," characterized by well- or moderatelydifferentiated cells, largely-preserved glandular structure, and normal or above-normal cellularity, or "high-grade," highly cellular lesions containing sheets of pleomorphic, poorly-differentiated cells (Figure 2C). This classification was performed in a similar manner as with human prostate clinical biopsies, as previously described [8, 30]. Supplementary Table 1 summarizes the composition of tumor based upon differentiation. Interestingly, 2 of the 10 mice contained distinctly separate regions of low- and high-grade cancer, as determined by histology, 
which also demonstrated differences in contrast on ${ }^{1} \mathrm{H}$ anatomical images (Figure 2, 3rd and 4th columns). These findings recapitulate features of human prostate cancer, where mixed tumors including both low- and high-grade components are common.

Tissue samples harvested after imaging also demonstrated differences in proliferation and hypoxia between high- and low-grade tumors, reflected in Ki-67 proliferation marker and pimonidazole (PIM) hypoxia marker staining (Figure 2D-2E). The ${ }^{1} \mathrm{H}$ ADC in highgrade tumors was significantly lower than in low-grade tumors ( $p=0.00252$, Figure 3A), likely reflecting the higher cellularity of high-grade prostate cancer, and the intensity of Ki-67 was significantly greater ( $p=$ 0.000666 , Figure 3B). PIM staining was not statistically significant between low- and high-grade lesions due to one outlier ( $p=0.103$ including outlier, $p=0.0104$ without; Supplementary Figure 1).

\section{Hyperpolarized imaging of glycolysis}

Because $\mathrm{pH}_{\mathrm{e}}$ may be dependent upon upregulation of glycolytic metabolism, we sought to quantify metabolic differences between low- and high-grade lesions.
Representative spatial maps of quantified lactate-topyruvate (Lac/Pyr) ratio from $\mathrm{HP}{ }^{13} \mathrm{C} \mathrm{MR}$ imaging overlaid upon conventional ${ }^{1} \mathrm{H}$ anatomical images of TRAMP tumors are shown in Figure 4A. The raw magnitude images corresponding to these overlays can be found in Supplementary Figure 2A. Based upon histological staining, regions of interest on images could be classified as low- or high-grade for statistical analysis. High-grade tumor regions generally displayed higher values of Lac/ Pyr compared with low-grade regions. Imaging statistics across all mouse tumor regions are compared between low- and high-grade in Figure 4B, revealing significant differences in mean Lac/Pyr ratio $(p=0.0303)$. The Lac/ Pyr ratio demonstrated a moderately strong negative correlation with ${ }^{1} \mathrm{H}$ ADC (Figure 4C), indicating that higher tumor cellularity may contribute to higher observed lactate conversion. Low- and high-grade tumors also demonstrated a significant difference in regionalmaximum Lac/Pyr voxel ratio $(p=0.0101$, Supplementary Figure 2B). We also performed quantitative RT-PCR in the same mice on tumor tissue excised after imaging in order to quantify expression of the Ldha gene (Supplementary Figure 2C). Ldha gene expression was lower in lowgrade lesions, but not statistically significant $(\mathrm{p}=0.0732)$.
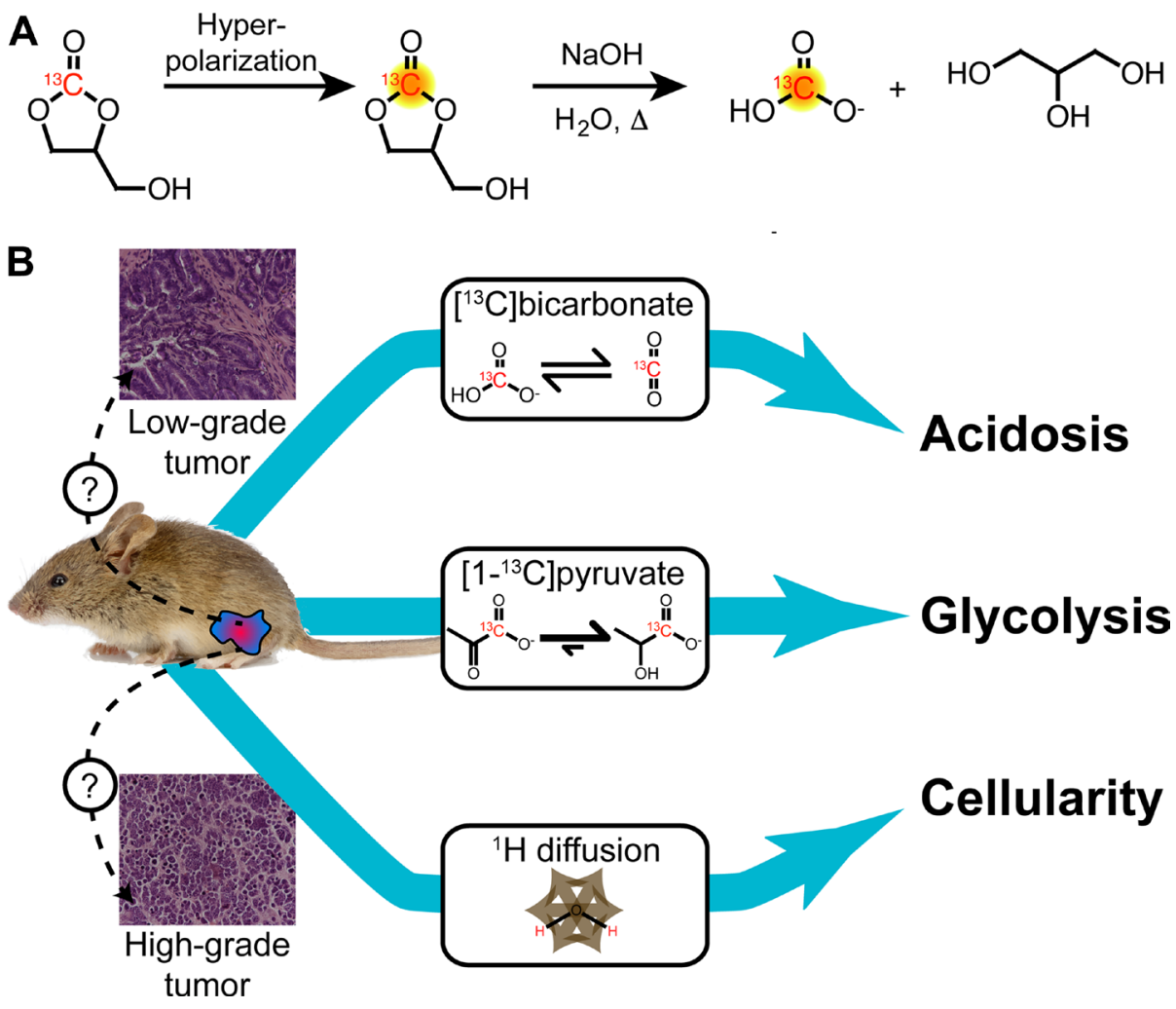

Figure 1: Schematic of multiparametric MR imaging protocol utilized in this work. (A) Hyperpolarized $\left[{ }^{13} \mathrm{C}\right]$ bicarbonate was obtained by polarizing $\left[1-{ }^{13} \mathrm{C}\right] 1,2$-glycerol carbonate, which was rapidly hydrolyzed immediately prior to injection using base and heat, followed by neutralization. This approach generates a $\mathrm{pH}$-neutral solution of $\mathrm{HP}\left[{ }^{13} \mathrm{C}\right]$ bicarbonate with high signal for in vivo $\mathrm{pH}$ imaging. (B) Transgenic mice with prostate lesions were subjected to ${ }^{1} \mathrm{H}$ diffusion-weighted imaging as well as two separate hyperpolarized ${ }^{13} \mathrm{C}$ injections of $\left[1-{ }^{13} \mathrm{C}\right]$ pyruvate and $\left[{ }^{13} \mathrm{C}\right]$ bicarbonate with MR spectroscopic imaging in a single imaging study. These imaging methods enabled measurement of tumor cellularity, glycolytic metabolism, and extracellular acidification, respectively. 
However, the two low-grade lesions that exhibited the highest Ldha expression came from the two mice that also included a high-grade lesion.

\section{Hyperpolarized imaging of extracellular acidification}

We investigated whether in vivo hyperpolarized $\mathrm{pH}$ imaging with $\left[{ }^{13} \mathrm{C}\right]$ bicarbonate could distinguish low- and high-grade tumor tissue. Figure 5A displays representative $\mathrm{pH}$ overlays obtained in the same imaging study as the hyperpolarized $\left[1-{ }^{13} \mathrm{C}\right]$ pyruvate imaging. The raw spectra and magnitude images corresponding to these overlays can be found in Supplementary Figure 3. Low- and high-grade tumor regions were differentiated by both their mean and regional-minimum $\mathrm{pH}$ values $(p=0.0177$ and 0.0101 , respectively, Figure 5B-5C). For low-grade tumors we found a mean and minimum $\mathrm{pH}$ of $7.53 \pm 0.17$ and $7.43 \pm 0.19$, respectively, and for highgrade tumors we found a mean and minimum $\mathrm{pH}$ of 7.22 \pm 0.14 and $7.06 \pm 0.12$, respectively. Only one low-grade lesion overlapped with the high-grade distribution when
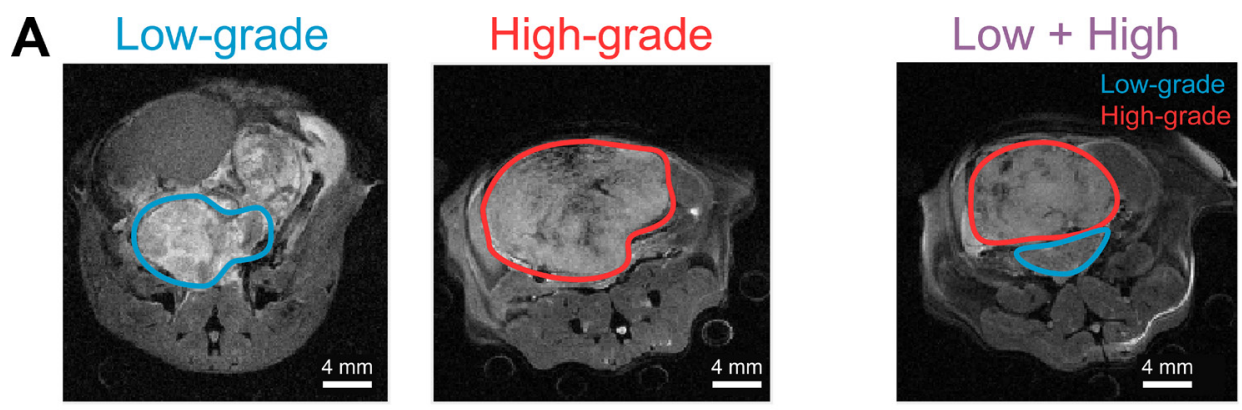

B
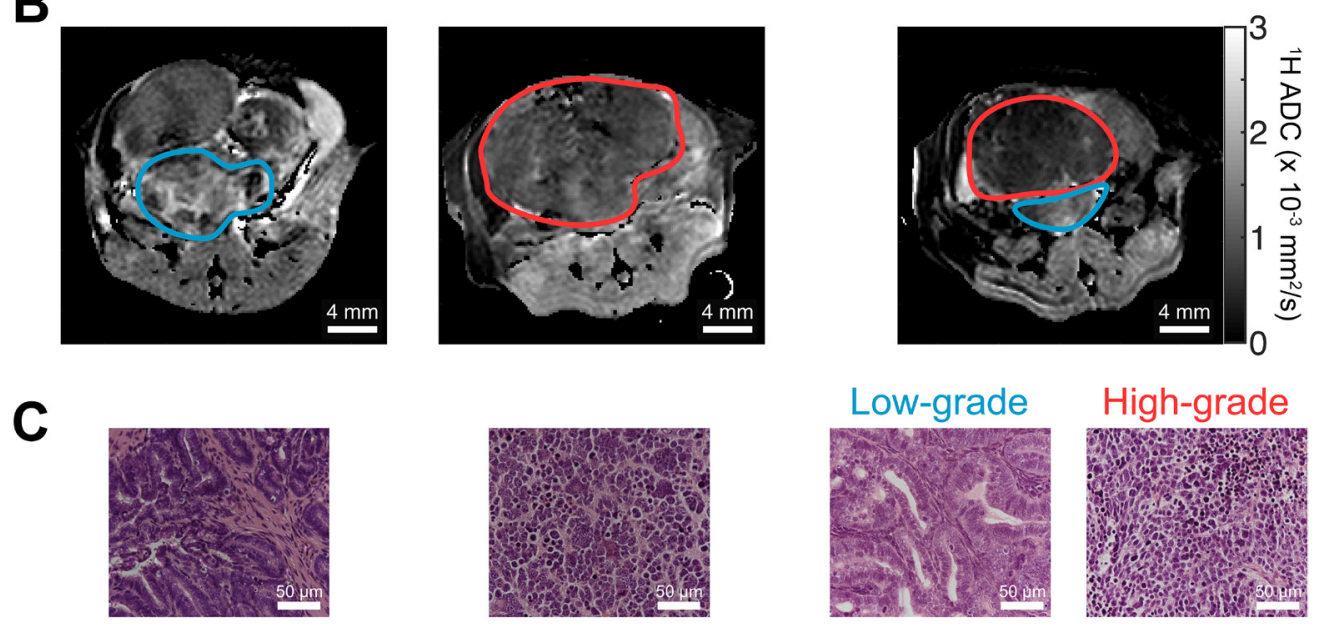

D
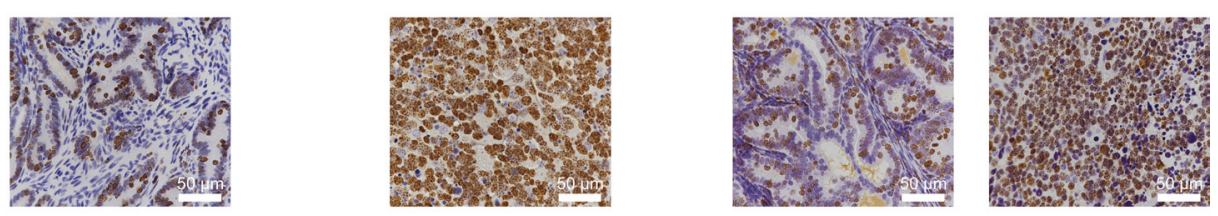

$\mathbf{E}$
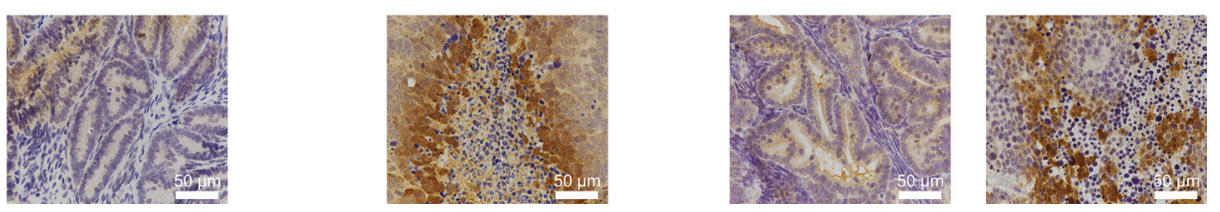

Figure 2: ${ }^{1} \mathrm{H}$ MR imaging and histological staining of TRAMP tumor tissue display differences in aggressive phenotype. (A) Anatomical ${ }^{~} \mathrm{H}$ MR images of TRAMP tumors during different stages of tumor progression, displaying predominantly low-grade lesions, predominantly high-grade lesions, and lesions with distinct low- and high-grade regions ("Low + High"), identified by MRI and confirmed via histology. These correspond with mice 2, 9, and 5, respectively, as listed in the Supporting Information and Methods, Supplementary Table 1. (B) ${ }^{1} \mathrm{H}$ apparent diffusion coefficient (ADC) maps for the same mice as in part (A), demonstrating a reduction in ADC in high grade tumors. (C-E) Tumor tissue corresponding with MRIs in parts (A-B) and stained with (C) H\&E; (D) Ki-67 proliferation marker stain; and (E) anti-pimonidazole hypoxia stain. Images demonstrate differences in morphology, cellularity, and hypoxia between low- and high-grade tumor tissues. All microscope images were acquired with $40 \times$ magnification. 

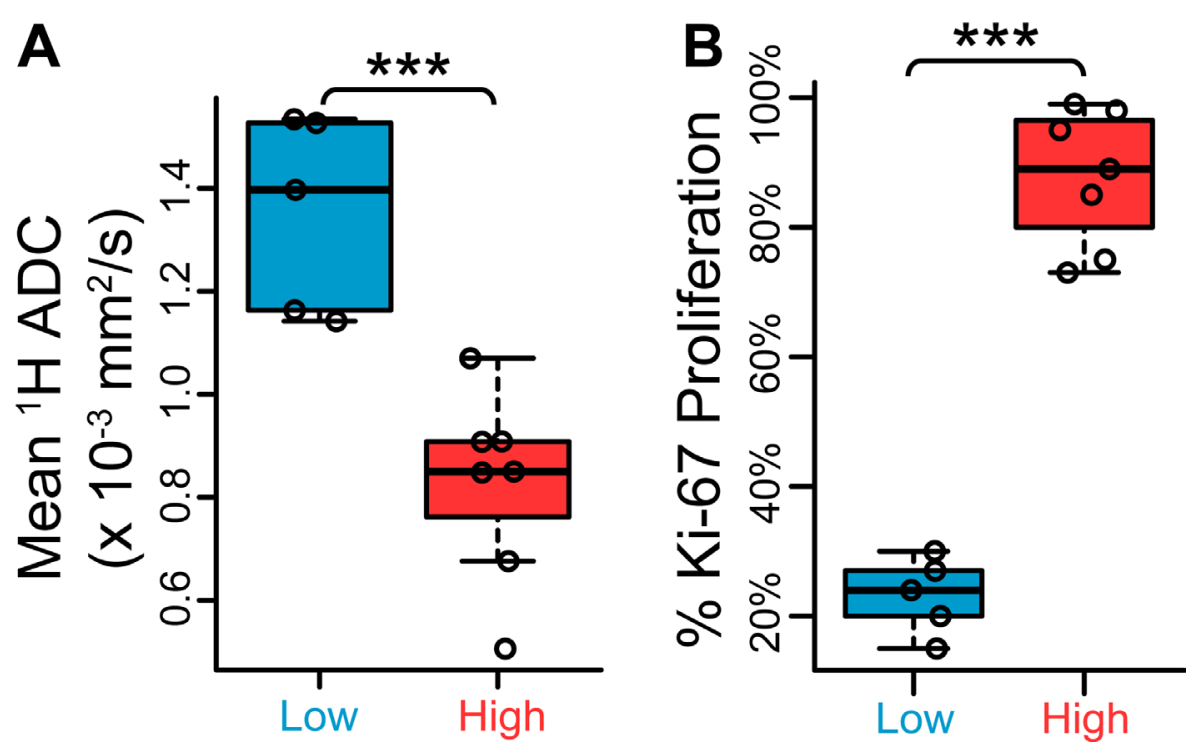

Figure 3: Low- and high-grade TRAMP lesions exhibit differences in ${ }^{1} \mathrm{H}$ apparent diffusion coefficient (ADC) and Ki-67 proliferation staining. (A) Scatter plots of mean ${ }^{1} \mathrm{H}$ ADC between low- and high-grade regions, demonstrating a statistically significant difference ( $n=5$ low-grade, $n=7$ high-grade). (B) Quantitative low- and high-grade comparison between percentage areas stained positive for Ki-67 nuclear stain ( $n=5$ low-grade, $n=7$ high-grade). $* * * p<0.005$.

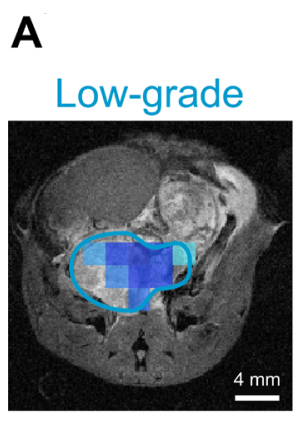

B

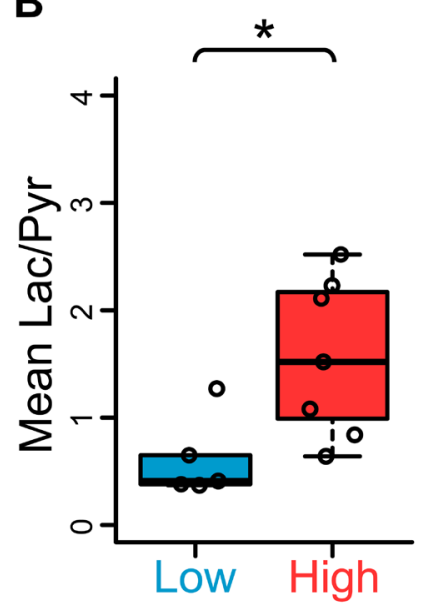

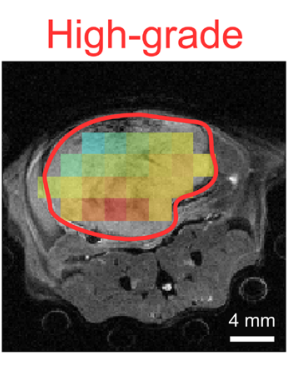

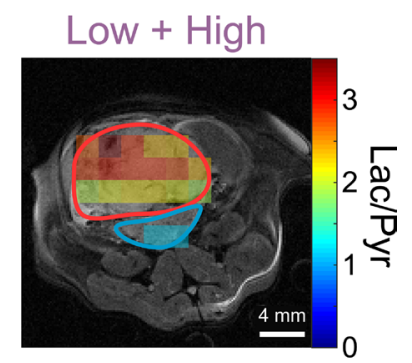

C

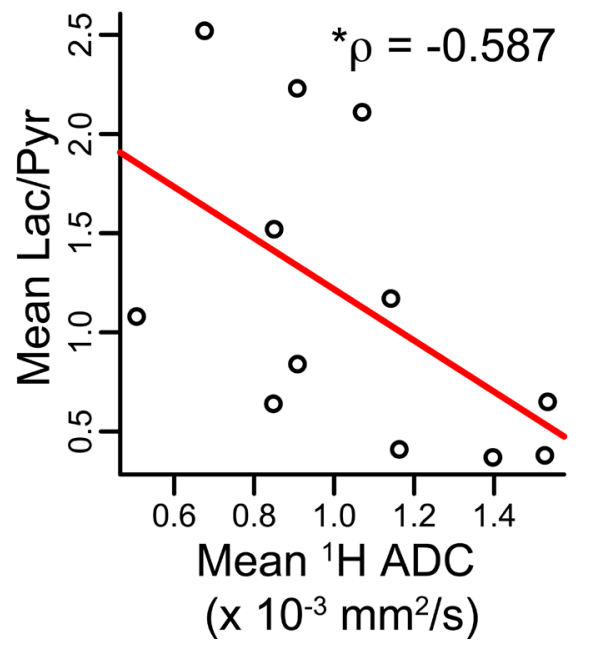

Figure 4: Hyperpolarized $\left[1-{ }^{13} \mathrm{C}\right]$ pyruvate imaging in TRAMP mice confirms glycolytic differences between low- and high-grade cancers. (A) Representative overlays of hyperpolarized lactate-to-pyruvate ratio (Lac/Pyr) for the mice displayed in Figure 2. (B) Scatter plots demonstrating a significant difference in mean Lac/Pyr ratio obtained from $\mathrm{HP}{ }^{13} \mathrm{C}$ images between low- and high-grade regions over all tumors ( $n=5$ low-grade, $n=7$ high-grade). (C) The mean Lac/Pyr ratio demonstrated a negative correlation with ${ }^{1} \mathrm{H}$ ADC for each tumor that was statistically significant $(p=0.0488) . * p<0.05$. 
looking at regional-minimum $\mathrm{pH}$ (Figure 5C). The tumor tissue close to the minimum $\mathrm{pH}$ voxel in this lesion had a histology index of 1.7 (Supplementary Figure 4), which was close to the cutoff value of 2 between low- and highgrade tumors and higher than the mean histology index of all low-grade lesions in the study (Supplementary Table 1).

\section{Correlation of multi-probe hyperpolarized imaging and gene expression results}

We investigated correlations between $\mathrm{pH}_{e}$ and lactate production based on HP imaging. The minimum voxel $\mathrm{pH}$ and maximum Lac/Pyr voxel ratio within each lesion demonstrated a strong negative correlation ( $\rho=-0.776, p=0.00466$, Figure 6A). There was a weak, non-statistically significant inverse correlation between mean imaging $\mathrm{pH}_{\mathrm{e}}$ and mean Lac/Pyr ratio per lesion ( $\rho=-0.469, p=0.128$; Supplementary Figure 5A). Pooling imaging voxels across all lesions together and fitting to a linear mixed-effects model, the $\mathrm{pH}_{\mathrm{e}}$ was found to be inversely correlated with the Lac/Pyr ratio in the same voxel with slope $-0.151 \mathrm{pH}$ unit/unit increase in Lac/Pyr ratio $\left(p=2.45 \times 10^{-8}\right.$; Figure $\left.6 \mathrm{~B}\right)$. The correlation between mean tumor $\mathrm{pH}_{\mathrm{e}}$ and Mct4 gene expression was strongly negative $(\rho=-0.806, p=0.00824$; Figure $6 \mathrm{C})$, suggesting that increased MCT4 expression is associated with decreased $\mathrm{pH}_{\mathrm{e}}$ in TRAMP tumors. There was an inverse correlation between mean $\mathrm{pH}_{\mathrm{e}}$ and Mct1 gene expression, although statistical significance was not observed $(\rho=-0.497, p=0.104$; Supplementary Figure 5B).

We also investigated whether there were gradedependent differences in expression of the Mct1, Mct4, and Hifl $\alpha$ genes. All three genes were significantly overexpressed in high-grade tissue compared with low-grade ( $p=0.00252,0.0333$, and 0.0480 for Mct1, Mct4 and Hifl $\alpha$, respectively; Supplementary Figure 6).

All imaging parameters demonstrated a large effect size between low- and high-grade lesions ( $\mid$ Cohen's $\mathrm{d} \mid>1.5$, Supplementary Table 2). Supplementary Figure 7 shows the distributions of mean ${ }^{1} \mathrm{H}$ ADC, mean HP Pyr/Lac, and mean/minimum HP pH between low- and high-grade lesions when including

A
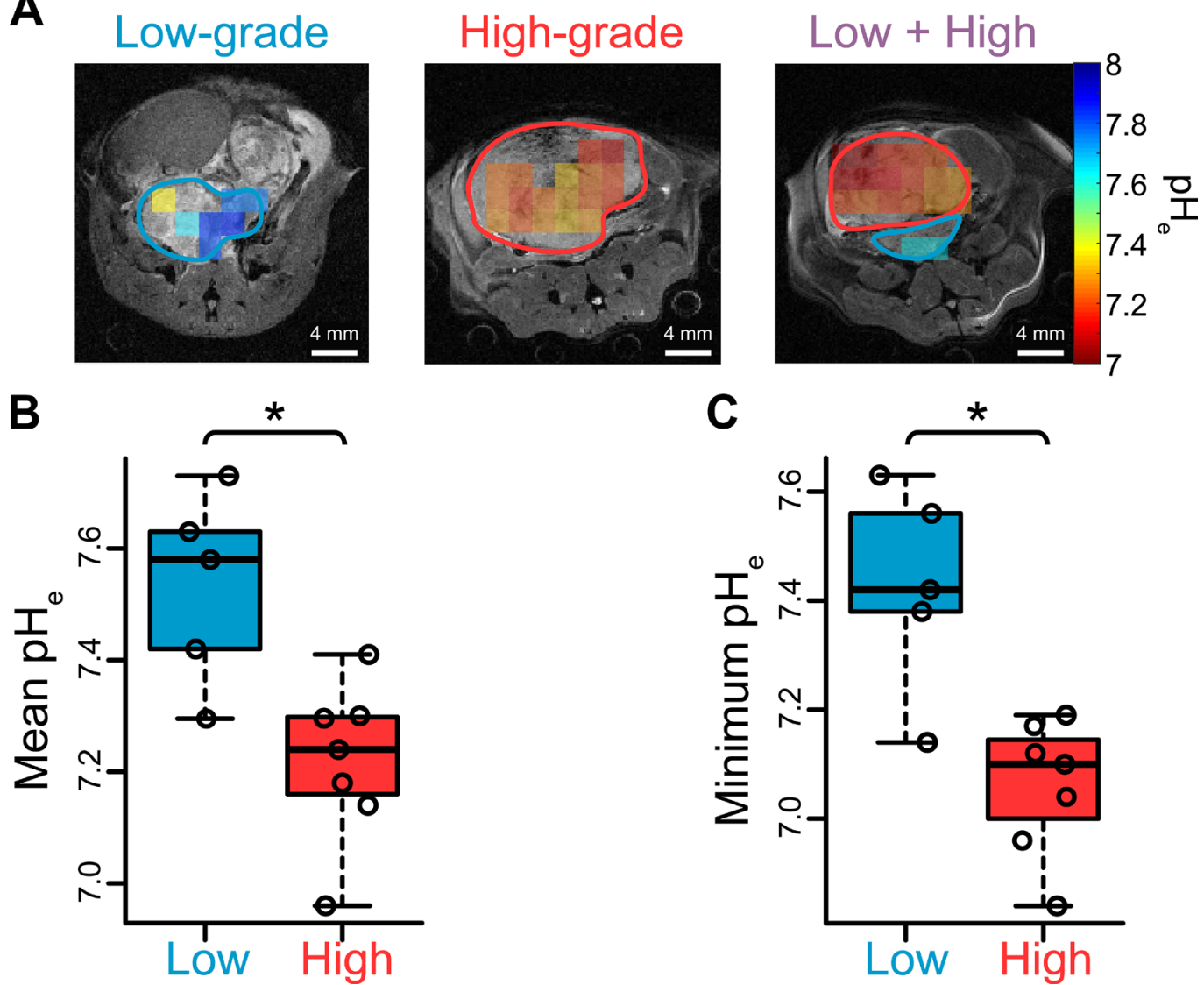

Figure 5: Extracellular pH measurements in TRAMP tumors via hyperpolarized $\left[{ }^{13} \mathrm{C}\right]$ bicarbonate imaging suggest extracellular acidification is associated with high-grade disease. (A) Representative overlays of extracellular $\mathrm{pH}$ measured with hyperpolarized $\left[{ }^{13} \mathrm{C}\right]$ bicarbonate for the mice displayed in Figure 2. (B-C) Scatter plots demonstrating significant differences in $\mathrm{pH}$ metrics obtained from $\mathrm{HP}{ }^{13} \mathrm{C}$ images between low- and high-grade regions over all mice: (B) mean; and (C) regional-minimum ( $n=5$ low-grade, $n=7$ high-grade). ${ }^{*} p<0.05$. 
only one imaging region of interest (ROI) per mouse. Differences between low- and high-grade imaging metrics were still statistically significant $\left(p<0.01\right.$ for ${ }^{1} \mathrm{H}$ ADC; $p<0.05$ for all others).

\section{DISCUSSION}

Extracellular $\mathrm{pH}$ is reduced in many cancers, both in humans and in animal models [17], and for many years $\mathrm{pH}$ electrodes have served as the predominant technology available for tissue $\mathrm{pH}$ measurement [17]. This is not a feasible option in the clinic due to its invasiveness as well as the possibility of perturbing the native $\mathrm{pH}$ environment during measurement. Changes in $\mathrm{pH}_{\mathrm{e}}$ have also been demonstrated to modulate cancer cell motility and aggressive phenotype [21]. There is a growing body of literature that also suggests that spatiotemporal changes in $\mathrm{pH}$ heterogeneity, measurable via molecular imaging techniques, may confer a survival advantage upon cancer cells in various aspects: therapeutic resistance, immune evasion, maintaining stemness and differentiation capacity, and extracellular matrix remodeling [32]. Furthermore, $\mathrm{pH}$ and metabolism are known to be closely connected and may affect one another. Therefore, a clinically translatable MRI protocol that can measure $\mathrm{pH}_{\mathrm{e}}$ simultaneously with metabolic markers may significantly improve clinical care of patients with prostate cancer.

In this study, we simultaneously assessed glycolysis and extracellular acidification in the TRAMP mouse in a single hyperpolarized imaging session and drew important
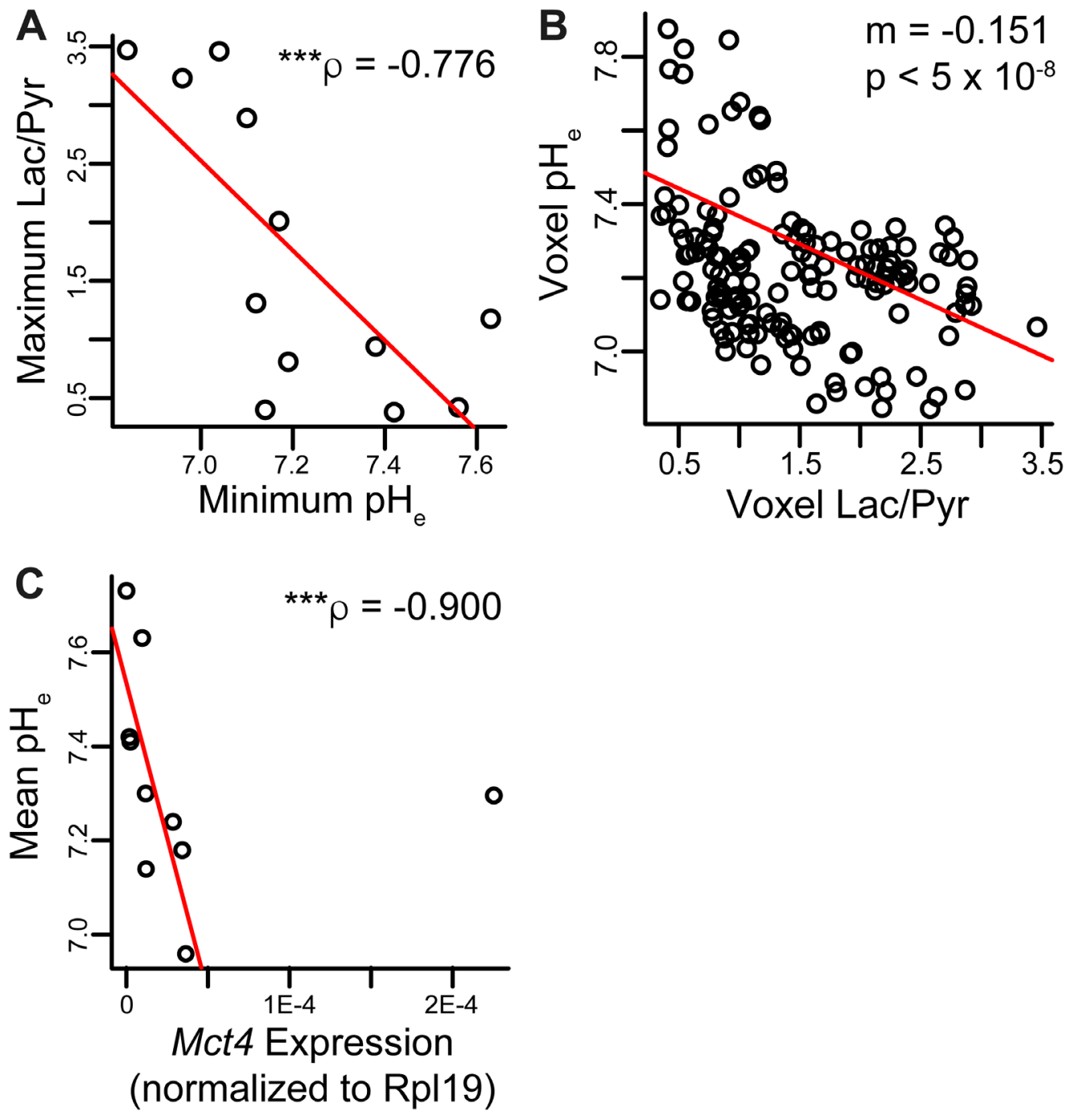

Figure 6: Correlations between metabolic parameters and $\mathbf{p H}_{\mathrm{e}} \mathrm{e}^{(\mathrm{A})}$ Spearman non-parametric regression between maximum $\mathrm{Lac} / \mathrm{Pyr}$ and minimum $\mathrm{pH}_{\mathrm{e}}$ in each $\mathrm{ROI}$ showed a strong negative correlation $\left(n=12\right.$ lesions). (B) The measured $\mathrm{Lac}_{\mathrm{Pyr}} \mathrm{Patio}$ and $\mathrm{pH}$ in each imaging voxel across all mice were negatively correlated. The $\mathrm{pH}$ decreased by about 0.15 unit per unit increase in Lac/Pyr ratio ( $n=153$ voxels). (C) Spearman non-parametric regression between mean $\mathrm{pH}$ and Mct 4 gene expression was strongly negative and statistically significant ( $n=10$ lesions). Two of the twelve lesions imaged had Mct4 gene expression levels below the threshold of quantification; these lesions had average $\mathrm{pH}_{\mathrm{e}}$ values of 7.30 and 7.56. $\rho$ and $p$-value in plot exclude the outlier; the correlation was still significant with outlier included $(p=0.00824) .{ }^{* * *} p<0.005$. 
links between the two. We have previously demonstrated that $\mathrm{HP}\left[{ }^{13} \mathrm{C}\right]$ bicarbonate can be generated via rapid breakdown of HP $\left[1-{ }^{13} \mathrm{C}\right] 1,2$-glycerol carbonate, and we showed that we could detect $\mathrm{pH}$ differences between benign and tumor tissue in a TRAMP mouse [22]. A notable advantage of this technique is the elimination of toxic $\mathrm{Cs}^{+}$as a counter-ion to improve bicarbonate solubility in the formulation, as has been used in previous HP reports $[25,33]$. Our research group has also shown in a dual-agent HP study applying $\mathrm{HP}\left[1-{ }^{13} \mathrm{C}\right]$ pyruvate and $\left[{ }^{13} \mathrm{C}\right]$ urea in low- and high-grade TRAMP tumors that TRAMP mice recapitulate key metabolic and histologic features of human prostate cancer. HP $\left[{ }^{13} \mathrm{C}\right]$ urea does not undergo metabolic conversion and therefore can be used to study tumor tissue perfusion via dynamic imaging. The study demonstrated a metabolism-perfusion mismatch in high-grade TRAMP tumors, in which regions of high HP lactate-to-pyruvate conversion demonstrated low area under the curve signal of HP urea [30]. Although the authors suggested that the high glycolytic conversion rate and low perfusion would likely contribute to extracellular acidification, they did not measure this in their cohort of TRAMP mice. The same two HP agents were utilized in a subsequent study along with multiparametric ${ }^{1} \mathrm{H}$ MRI in a different cohort of TRAMP mice displaying normal prostate, low-grade tumors, and high-grade tumors [14]. Similarly, the authors observed a higher HP lactate-topyruvate ratio as well as a lower HP urea signal in highgrade tumors compared with both low-grade and normal prostate. A lower $\mathrm{pH}_{\mathrm{e}}$ was once again implied but not explicitly measured in this cohort of TRAMP mice. In this study, we have included in vivo hyperpolarized $\left[{ }^{13} \mathrm{C}\right]$ bicarbonate $\mathrm{pH}$ imaging in a new cohort of low- and high-grade TRAMP tumors and confirmed that $\mathrm{pH}_{\mathrm{e}}$ is significantly reduced in aggressive tumors (7.06 for highgrade versus 7.43 for low-grade).

One of the major findings of this work was that both mean and regional-minimum tumor $\mathrm{pH}$ obtained via imaging varied significantly between low- and highgrade lesions (Figure 5B-5C). Within the two mice that exhibited separate low- and high-grade tumor regions, the $\mathrm{ROI}$ mean and minimum $\mathrm{pH}$ values were both lower in the high-grade lesion, enabling separation of benign and aggressive cancer within the same mouse. This is similar to the human prostate, which may demonstrate a mixture of low- and high-grade cancer in various regions throughout the organ. A minimum-pH quantification scheme is encouraging in that it may be more robust to variation in ROI definition than a mean-pH quantification scheme. It may also demonstrate greater sensitivity to the presence of high-grade cancer within an imaging ROI, considering that greater acidity is closely linked with a more aggressive phenotype in cancer $[21,34]$. In support of this rationale, the minimum-pH quantification scheme was able to identify a "biopsy site" within a lesion that was grossly characterized as low-grade, revealing a region of predominantly moderately-differentiated tumor cells (Supplementary Figure 4). Thus, it is likely in this case that hyperpolarized $\mathrm{pH}$ imaging was able to identify a lesion in this mouse that was on the cusp of developing into aggressive cancer. Our other results are in agreement with previous experimental findings. Compared with low-grade TRAMP tumors, high-grade tumors demonstrated higher proliferation and hypoxia [14, 30], a lower mean ${ }^{1} \mathrm{H}$ ADC [14], altered hyperpolarized lactate imaging parameters [8, $14,30,35]$, and upregulated gene expression of glycolytic enzymes and transporters, including Ldha, Mct1/4, and Hifl $\alpha[14,30]$. Unlike the human situation, the mean ADC of the TRAMP tumors showed very good separation between low- and high-grade lesions (Figure 3A), which likely reflects the dramatic differences in cellularity observed histologically (Figure 2C).

We observed a strong negative correlation between mean $\mathrm{pH}$ and Mct4 gene expression in the lesions studied (Figure 6B), implicating the MCT4 transport protein, which exports lactic acid, as a contributor to extracellular acidosis. There was one outlier: a lesion with very high Mct4 expression but an alkaline mean $\mathrm{pH}_{\mathrm{e}}$ value of 7.30 . This lesion was smaller in volume that other high-grade lesions, and therefore the high HP signal arising from nearby vascular voxels may have spilled over, causing the lesion $\mathrm{pH}_{\mathrm{e}}$ to appear more alkaline. In contrast with Mct4, we did not detect as strong of a correlation between $\mathrm{pH}$ and the Mct1 gene (Supplementary Figure 5B), reflecting the specific association of the MCT4 transporter with high lactate efflux [36-39]. We also detected a statistically significant correlation between $\mathrm{pH}_{\mathrm{e}}$ and lactate production as measured by hyperpolarized imaging, both on a perlesion basis (Figure 6A) and on a per-voxel basis (Figure $6 \mathrm{~B})$. We did not observe a perfect overlap between high lactate production and low $\mathrm{pH}_{\mathrm{e}}$, but this is not unexpected given the known complexity of extracellular acidity, which is a consequence of transport of protons via multiple transporters [18], interstitial buffering capacity [40], proton exchange kinetics and motility [41], and tissue perfusion [42]. We present a model of TRAMP tumor progression in Figure 7 that summarizes the observed lactate, $\mathrm{pH}$, and gene expression correlations. In low-grade tumors, there is relatively little production of lactate as measured with hyperpolarized $\left[1-{ }^{13} \mathrm{C}\right]$ pyruvate imaging $[8,14,30]$ (Figure 4) and a normal $\mathrm{pH}_{\mathrm{e}}$ of 7.43 (Figure 5). In contrast, high-grade tumors demonstrate increased production of lactate (Figure 4) by lactate dehydrogenase $[8,14,30]$, increased expression of MCT4 [14, 30], and a decreased $\mathrm{pH}_{\mathrm{e}}$ of 7.06 (Figure 5). This model reflects the correlations observed between increased lactic acid production, decreased extracellular $\mathrm{pH}$, and disease grade in the TRAMP model.

Several limitations of our study design are worth mentioning. First, the coarse spatial resolution of hyperpolarized $\mathrm{pH}$ imaging ( $4 \mathrm{~mm}$ in-plane, $6.5 \mathrm{~mm}$ slice) meant that some voxels contained a mixture of various 
tissue types, including benign and aggressive tumor as well as stromal tissue. Nevertheless, this resolution was sufficient for us to capture tumor $\mathrm{pH}$ heterogeneity. Advances in hyperpolarization and MR imaging may be able to reduce the achievable voxel size and thus better isolate tissue components. Second, our study cohort of mice was too small $(n=10)$ to detect significant differences in PIM staining and Ldha gene expression as in prior literature $[14,30]$. However, the two low-grade tumors with the highest Ldha expression came from the two mice with high-grade lesions as well, perhaps due to the unintentional inclusion of nearby high-grade tissue in the sample. Despite the small cohort size, differences in imaging parameters between low- and high-grade tumors, and the majority of the gene expression data, demonstrated statistical significance. Third, we did not include mice with normal prostates in our study, primarily because we did not have sufficient imaging spatial resolution to sufficiently capture it. This does not change the significance of the finding that low- and high-grade tumors demonstrate significantly different $\mathrm{pH}_{\mathrm{e}}$ values. Finally, all tumor regions were treated as independent samples, even though some regions analyzed came from the same mouse. In order to correct for this potential source of error, we performed a per-mouse analysis and still detected significant differences in mean ${ }^{1} \mathrm{H}$ ADC, mean HP Pyr/Lac, and mean/minimum HP pH (Supplementary Figure 7).

Hyperpolarized $\mathrm{pH}$ imaging may significantly improve clinical management of prostate cancer. Current standard-of-care prostate cancer multiparametric MRI includes $\mathrm{T}_{2}$ - and diffusion-weighted imaging and dynamic contrast-enhanced imaging, interpreted using the Prostate Imaging Reporting \& Data System (PI-RADS) framework [43-45]. This method is highly effective in detecting prostate cancer and localization for subsequent biopsy, but it can miss small volumes of high-grade disease and fail to reliably grade lesions based on imaging characteristics [4, 46-48]. In particular, although ${ }^{1} \mathrm{H}$ diffusion-weighted imaging is sensitive to detect highly cellular late-stage lesions [49], false positives can arise from tissue compression or high stromal composition [50]. Furthermore, imaging parameters can be compromised by biopsy of the imaging site [50]. We are unaware of other pathological conditions that may cause interstitial acidification in prostate cancer and confound $\mathrm{HP} \mathrm{pH}_{\mathrm{e}}$ imaging results. In contrast, a high degree of alkalinization of human prostatic fluid has been observed with prostatic infection [51]. Hyperpolarized $\left[1-{ }^{13} \mathrm{C}\right]$ pyruvate imaging has been applied in men with prostate cancer, with the key
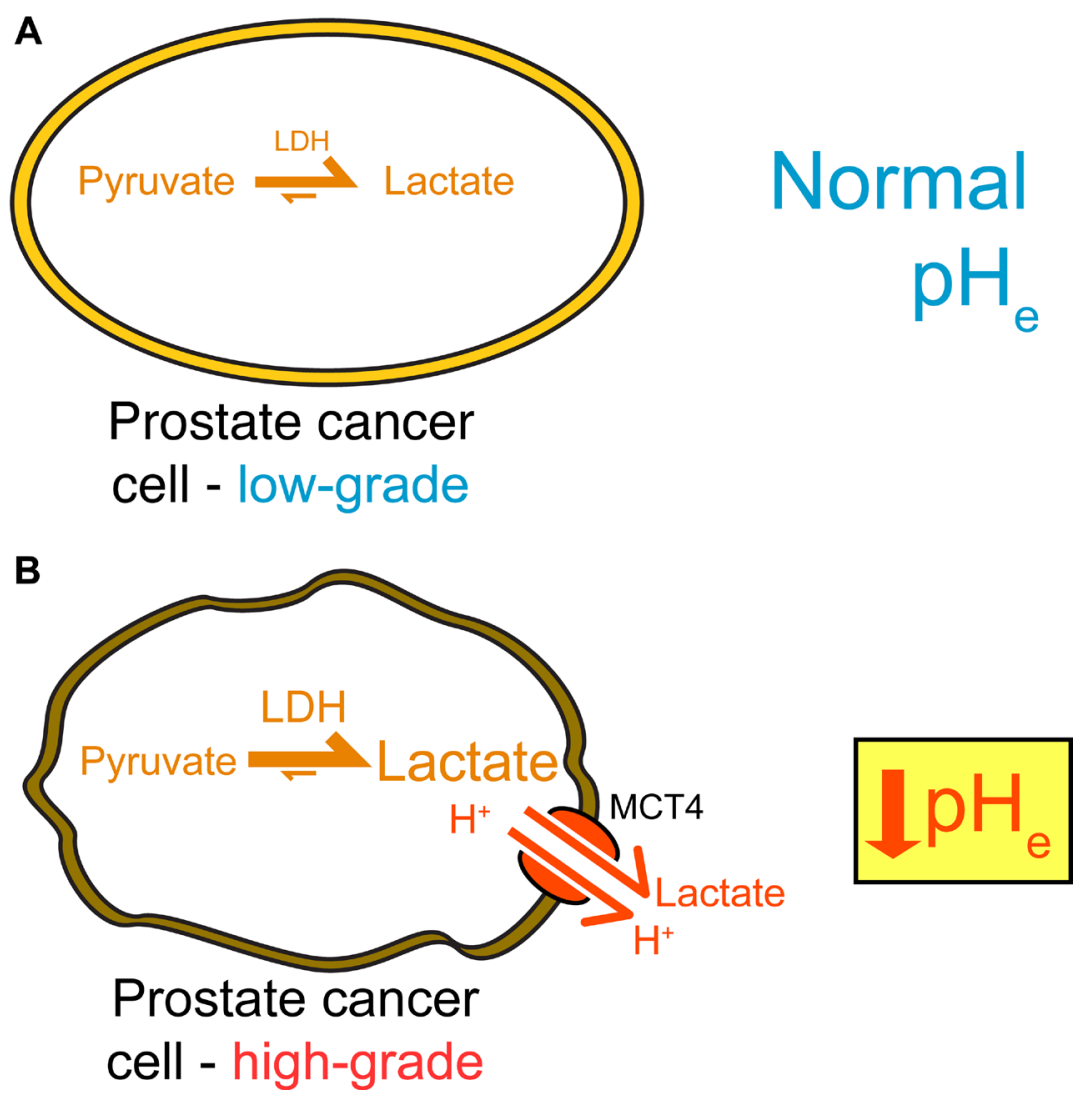

Figure 7: Summary of imaging and gene expression findings in TRAMP tumors. High-grade disease exhibits a metabolic shift and extracellular acidification, which can both be detected through imaging with hyperpolarized ${ }^{13} \mathrm{C}$ methods. (A). Low-grade tumors demonstrate low levels of LDH activity, low lactate production, and a normal $\mathrm{pH}_{\mathrm{e}}$. (B) High-grade TRAMP tumors upregulate LDHA, produce increased lactate, upregulate $\mathrm{MCT} 4$, and have a lower $\mathrm{pH}_{\mathrm{e}}$. 
finding of increased lactate production in tumors [10]. It is worth noting that HP imaging not only can be completed more quickly than other types of metabolic MRI (one or two minutes compared with 10-30 minutes), but it also boasts the potential capability of imaging multiple HP agents simultaneously in a single scan [11]. We have extended hyperpolarized in vivo imaging beyond pyruvate alone to also include imaging of $\left[{ }^{13} \mathrm{C}\right]$ bicarbonate in the same imaging session, aided by recent advances in the underlying polarization techniques and chemistry [22].

The HP bicarbonate imaging method utilized in this study holds promise for eventual clinical translation. While other HP compounds have demonstrated promise for measuring $\mathrm{pH}_{\mathrm{e}}$ in vivo, including $\mathrm{N}$-(2-acetamido)-2aminoethanesulfonic acid (ACES) [26], diethylmalonic acid (DEMA) [27], zymonic acid [52], and amino acid derivatives [52], bicarbonate is routinely infused into patients at high concentration and therefore has a low barrier to entry. Nevertheless, significant challenges exist. One prominent challenge is the short in vivo spin-lattice relaxation time constant $\left(\mathrm{T}_{1}\right)$ of $\left[{ }^{13} \mathrm{C}\right]$ bicarbonate $(10 \mathrm{~s})$ $[11,25]$. Another is the relatively slow kinetic conversion between bicarbonate and $\mathrm{CO}_{2}$, which requires sufficient time to reach equilibrium $\mathrm{pH}$ and depends upon expression and localization of carbonic anhydrase (CA) isoforms. We have previously measured the characteristic exchange rate constant for bicarbonate- $\mathrm{CO}_{2}$ to be $1.56 \mathrm{~s}^{-1}$ in high-grade TRAMP tumors [53], which suggests that $\mathrm{pH}$ equilibrium is reached $(95 \%)$ in $\sim 2 \mathrm{~s}$. Bicarbonate- $\mathrm{CO}_{2}$ exchange might be slower in low-grade tumors if extracellular CA isoforms are not as strongly expressed, although we have not measured either exchange or CA expression in lowgrade tumors. Some HP bicarbonate and $\mathrm{CO}_{2}$ in a given voxel may also distribute between erythrocytes, blood plasma, and tumor cytoplasm, meaning that the measured $\mathrm{pH}$ is not strictly extracellular. These effects, individually or in combination, may have given rise to the unusually high $\mathrm{pH}_{\mathrm{e}}$ values observed in low-grade lesions (Figure $5 \mathrm{~B})$. Despite these challenges, the GLC method of $\left[{ }^{13} \mathrm{C}\right]$ bicarbonate production used in this manuscript enables production of a polarized solution, similar to pyruvate, when prepared with the same methods (18\% for pyruvate vs. $19 \%$ for bicarbonate). Moreover, the method produced high quality, high-resolution maps of $\mathrm{pH}_{\mathrm{e}}$ (Figure 5). Finally, recent advances in pulse sequence acquisition promise to increase the signal-to-noise ratio of this method [53]. Taken together, these observations suggest the potential feasibility and utility of using hyperpolarized ${ }^{13} \mathrm{C}_{\mathrm{pH}}$ imaging for detecting aggressive disease in men with localized prostate cancer.

In conclusion, we conducted hyperpolarized imaging in transgenic prostate cancer mice in order to simultaneously obtain measures of glycolytic metabolism and $\mathrm{pH}_{\mathrm{e}}$. We observed significant differences in both Lac/Pyr ratio and $\mathrm{pH}_{\mathrm{e}}$ between histologically classified low- and high-grade tumors, consistent with increased expression of glycolytic enzymes and transporters in highgrade compared with low-grade tissue samples. These results suggest that hyperpolarized $\mathrm{pH}_{\mathrm{e}}$ imaging may be able to stratify low-risk and high-risk prostate cancer patients in a non-invasive exam.

\section{MATERIALS AND METHODS}

Additional experimental details may be found in the Supplementary Materials.

\section{Chemicals and ${ }^{13} \mathrm{C}$ imaging agent formulations}

$\left[1-{ }^{13} \mathrm{C}\right] 1,2$-glycerol carbonate (GLC) was purchased from Cambridge Isotopes Laboratories, Inc. (Tewksbury, MA, USA). $\left[1-{ }^{13} \mathrm{C}\right]$ pyruvic acid was purchased from Isotec (Miamisburg, OH, USA). The OX063 and GE trityl radicals were purchased from Oxford Instruments (Abingdon, UK). Other chemicals and solvents were purchased from Aldrich (St. Louis, MO, USA). GLC was formulated for hyperpolarization as previously described [22] and consisted of $15 \mathrm{mM}$ OX063 radical dissolved in the neat liquid. $\left[1-{ }^{13} \mathrm{C}\right]$ pyruvic acid was also formulated as previously described [11].

\section{Animal protocol and handling}

All animal studies were conducted in accordance with the policies of the Institutional Animal Care and Use Committee (IACUC) at the University of California, San Francisco. Transgenic adenocarcinoma of the mouse prostate (TRAMP) model mice [29] were supplied by Roswell Park Cancer Institute (Buffalo, NY, USA). This mouse model was chosen because it is known to recapitulate features of human prostate cancer that are relevant to this study, including progression from a lowgrade to a high-grade phenotype, as characterized by histopathology [31], as well as a metabolic switch to glycolytic metabolism in higher-grade disease [8, 14, $30,54]$. Mice were cannulated in the lateral tail vein and anesthetized with $1-2 \%$ isoflurane $/ 100 \%$ oxygen at a rate of $1 \mathrm{~L} / \mathrm{min}$. The anesthetized mouse was secured in an MR-compatible holder with a $37^{\circ} \mathrm{C}$ water pad and placed within the vertical bore of the imaging system. Every 10-12 minutes, the catheter was flushed with $8 \mu \mathrm{g} / \mathrm{mL}$ heparin in normal saline to prevent clotting. The mouse was given at least 15 minutes of recovery time between subsequent injections.

\section{Animal MR imaging protocol}

All MR imaging was performed on a vertical-bore $14 \mathrm{~T}$ Varian MR imaging system $\left(150 \mathrm{MHz}{ }^{13} \mathrm{C}\right.$, Varian Instruments). ${ }^{1} \mathrm{H}$ diffusion-weighted spin-echo axial images covering the entire tumor volume $\left(40 \times 40 \mathrm{~mm}^{2}\right.$ $[128 \times 128$ matrix $]$ in-plane, $1 \mathrm{~mm}$ slice thickness, 0.25 
mm slice spacing, $4 \mathrm{~b}$-values between 0 and $515 \mathrm{~s} / \mathrm{mm}^{2}$ ) were acquired using a $40 \mathrm{~mm}{ }^{1} \mathrm{H}$ quadrature millipede coil (Agilent Technologies, Palo Alto, CA, USA). All other imaging data were acquired with a $40 \mathrm{~mm}$ dual-tuned ${ }^{1} \mathrm{H} /{ }^{13} \mathrm{C}$ quadrature birdcage coil ( $\mathrm{m} 2 \mathrm{~m}$ Imaging, Cleveland, $\mathrm{OH}) .{ }^{1} \mathrm{H}$ axial and coronal images were acquired either prior to hyperpolarized injections or inbetween. Each mouse received two injections of $\mathrm{HP}{ }^{13} \mathrm{C}$ imaging agent: $100 \mathrm{mM}\left[{ }^{13} \mathrm{C}\right]$ bicarbonate produced via rapid hydrolysis of $\mathrm{HP}\left[1-{ }^{13} \mathrm{C}\right] \mathrm{GLC}$, as previously described [22], and 80 $\mathrm{mM}$ sodium $\left[1-{ }^{13} \mathrm{C}\right]$ pyruvate in $40 \mathrm{mM}$ TRIS buffer. Both agents were polarized using a HyperSense preclinical polarizer (Oxford Instruments, Abingdon, UK). The mean back-calculated polarization values for $\left[1-{ }^{13} \mathrm{C}\right]$ pyruvic acid and $\left[{ }^{13} \mathrm{C}\right]$ bicarbonate (generated from $\left[1-{ }^{13} \mathrm{C}\right] \mathrm{GLC}$ ) were $18 \%$ and $19 \%$, respectively. Approximately $450 \mu \mathrm{L}$ of agent were injected via the tail vein catheter over 15 $\mathrm{s}$ for pyruvic acid and $12 \mathrm{~s}$ for $\left[{ }^{13} \mathrm{C}\right]$ bicarbonate. For the $\left[{ }^{13} \mathrm{C}\right]$ bicarbonate injection, a $2 \mathrm{D}$ chemical shift imaging (2D CSI) sequence was performed 16-18 s after the start of injection $(8 \times 8 \times 256$ matrix size, 6.5 or $10 \mathrm{~mm}$ axial slice thickness, centric phase encoding, FOV $=32 \times 32$ $\mathrm{mm}^{2}, 8013 \mathrm{~Hz}$ spectral width, $\mathrm{TR}=67 \mathrm{~ms}$, total imaging time $\sim 4 \mathrm{~s}$ ). To avoid chemical shift misregistration between bicarbonate $/ \mathrm{CO}_{2}$ slices, a two-band Gaussian excitation pulse was used, which delivered nominal tip angles of $25^{\circ}$ and $2.78^{\circ}$ to $\mathrm{CO}_{2}$ and bicarbonate, respectively [22]. The ratio of signal excitation between the two pulse bands, necessary for calculating $\mathrm{pH}$ maps, was empirically determined beforehand using a spherical $\left[{ }^{13} \mathrm{C}\right]$ urea phantom. For the $\left[1-{ }^{13} \mathrm{C}\right]$ pyruvate injection, a single-shot 3D gradient-spin echo (3D GRASE) sequence [55] was used to obtain metabolite maps of pyruvate and lactate $(6 \mathrm{~ms}$ SLR excitation + refocusing pulses, $40 \times 40$ $\times 40 \mathrm{~mm}^{3} \mathrm{FOV}, 12 \times 12 \times 16$ matrix, center-out encoding in 2 nd phase-encode dimension, total time/metabolite $=$ $156 \mathrm{~ms})$. The 3D GRASE sequence was initiated $36 \mathrm{~s}$ after the start of injection.

\section{Image processing}

More details are available in the Supplementary Materials. The ${ }^{1} \mathrm{H}$ apparent diffusion coefficient (ADC) maps were generated along with root mean square (RMS) residuals using VnmrJ 4.2A software (Agilent Technologies, Palo Alto, CA, USA). The $2 \mathrm{D}$ CSI ${ }^{13} \mathrm{C}$ imaging data were processed using SIVIC open-source software (Sourceforge. net) [56]. All other imageprocessing steps, described below, were performed using custom MATLAB scripts (MathWorks, Natick, MA, USA).

Calculated ADC maps from ${ }^{1} \mathrm{H}$ diffusion-weighted imaging were thresholded using an upper limit of 500 for the RMS residual. All volume elements (voxels) with ADC $>3.0 \times 10^{-3} \mathrm{~mm}^{2} / \mathrm{s}$, the diffusion coefficient of free water at $37^{\circ} \mathrm{C}$ [57], were also excluded from analysis. ROIs were then drawn on each ${ }^{1} \mathrm{H}$ imaging slice, with each ROI being designated as either low-grade or high-grade tumor, based on histology. Low-grade and high-grade ROI data were combined across both mice, and the ADC values were extracted from the ROIs and used for statistical analysis.

HP image reconstruction was conducted similar to prior reports [14]. Briefly, all HP images were reconstructed to an in-plane spatial resolution of $2 \times 2$ $\mathrm{mm}^{2}$ and aligned. Axial slices of the pyruvate and lactate 3D GRASE images were averaged together in order to match the 2D CSI slice thickness for bicarbonate $/ \mathrm{CO}_{2}$. The lactate magnitude images were thresholded to exclude voxels with $\mathrm{SNR}<4$, whereas pyruvate voxels with $\mathrm{SNR}<4$ were set to the mean noise magnitude. Lactateto-pyruvate ratio ( $\mathrm{Lac} / \mathrm{Pyr}$ ) maps were then calculated from the pyruvate and lactate magnitude images. $\left[{ }^{13} \mathrm{C}\right]$ bicarbonate and $\mathrm{CO}_{2}$ magnitude peak integral images were thresholded to exclude voxels with $\mathrm{SNR}<3$, and the intensities were corrected based upon the difference in tip angle before $\mathrm{pH}$ calculation using a modified HendersonHasselbalch equation [22].

Voxels for analysis were selected using the axial and coronal anatomical images and designated as part of either a low-grade or high-grade ROI. Only voxels comprised of at least $50 \%$ tumor based on ${ }^{1} \mathrm{H}$ anatomical images and histology were included.

\section{Histological staining and qRT-PCR}

Mice were euthanized and dissected within 48 hours of imaging. For hypoxia staining, mice were injected with $60 \mathrm{mg} / \mathrm{kg}$ pimonidazole- $\mathrm{HCl} \quad 45-60$ minutes prior to euthanasia. During dissection, visually distinct tumor tissue samples were identified by a uro-oncologist (R. B.) highly experienced in murine pathology based upon tissue coloration, texture, density, and morphological distortion distinguishing them from normal genitourinary organ structure. Tissue samples were excised with their relative location noted (anterior/ posterior, lateral side, ventral/dorsal with reference to normal genitourinary organs including urethra and seminal vesicles) and/or photographed for matching later on with anatomical MR images. Excised tumor tissue samples were immediately fixed in $10 \%$ buffered formalin or flash-frozen with liquid nitrogen. Tissue staining was performed on $4 \mu \mathrm{m}$-thick sections using hematoxylin and eosin (H\&E, Thermo Scientific, Waltham, MA, USA), anti-Ki-67 (Cell Signaling Technology, Danvers, MA, USA), or anti-pimonidazole mouse IgG1 monoclonal antibody (Hypoxyprobe Inc., Burlington, MA, USA) on step sections. For very large tumors extending beyond the axial slice thickness of the ${ }^{13} \mathrm{C}$ imaging, the tissue section used for histology did not necessarily correspond with the MR imaging volume. A histologic index for each tissue sample was calculated, similar to previous studies [8, 14, 30], based on the weighted percentages of tumor differentiation (normal, 
well-differentiated, moderately well-differentiated and poorly-differentiated) from standard H\&E staining. The histologic index ranged between 0 and 3, where 0 indicated that $100 \%$ of the tissue was normal and 3 indicated that $100 \%$ of the tissue was poorly differentiated. Each tumor received a gross histological index by calculating the mean of all matched tissue samples, then was dichotomized to be either low-grade (index $\leq 2$ ) or high-grade (index $>2$ ), as previously described [14], in a manner that mimics the clinical pathologic practice in which patients with Gleason score $\leq 3+3$ are considered to have low-grade compared to Gleason $\geq 3+4$ high grade tumors.

The degree of Ki-67 and pimonidazole staining was determined for each tumor as follows. The approximate percentage of cells stained positive for $\mathrm{Ki}-67$ in viable tumor areas across an entire, representative cross-sectional specimen of each tumor was assessed visually by an experienced TRAMP pathologist, taking multiple, highpower/small-field cell counts from across the specimen. For pimonidazole, the percentage of positively stained cellular areas was similarly obtained across an entire, representative cross-section specimen of each tumor. If multiple specimens from the same tumor region were available, these Ki-67 and pimonidazole percentages were averaged.

For qRT-PCR, total RNA was extracted from snap-frozen tumor tissue using an RNeasy kit (Qiagen, Limburg, Netherlands) and measured using an RNA6000 Kit (Agilent, Santa Clara, CA, USA). The RNA extract was then subjected to RQ1 RNAse-free DNAse (Promega Manufacturing, Madison, WI, USA) in order to digest in-sample gDNA. Reverse transcription was performed with a qScript DNA Synthesis Kit (Quanta Biosciences, Gaithersburg, MD, USA), and subsequent quantitative RT-PCR was performed in triplicate using 96-well plates in a PikoReal real-time PCR system (Thermo Scientific, Waltham, MA, USA). qPCR probes (TaqMan, Life Technologies, Carlsbad, CA, USA) were selected for the following genes: lactate dehydrogenase subunit Ldha, monocarboxylate transporters (Mct1, Mct4), and hypoxiainducible factor Hifl $\alpha$. Expression was normalized to the 60S ribosomal protein L19 (Rpl19) gene in each sample.

\section{Statistical analysis}

All statistical analyses were performed using $\mathrm{R}$ software (The R Foundation; for package citations please see Supplementary Materials) [58]. Mean or minimum ROI voxel values were reported for each tumor. Low- and highgrade tumors were compared using nonparametric MannWhitney $U$ tests. Spearman correlations between data sets were estimated across all tumor samples. The correlation between the $\mathrm{Lac} / \mathrm{Pyr}$ ratio and $\mathrm{pH}_{\mathrm{e}}$ across all voxels was assessed by constructing a linear mixed-effects model accounting for individual lesions and mice. The Cohen's d-statistic for effect size was calculated for all imaging parameters. Statistics were reported in the text as mean \pm standard deviation. A $p$-value less than 0.05 was considered statistically significant.

\section{Abbreviations}

$\mathrm{pH}_{\mathrm{e}}$ : Extracellular $\mathrm{pH}$; HP: Hyperpolarized; TRAMP: Transgenic adenocarcinoma of the mouse prostate; ADC: Apparent diffusion coefficient; MR: Magnetic resonance; MRI: Magnetic resonance imaging; DNP: Dynamic nuclear polarization; PIM: Pimonidazole; LDH: Lactate dehydrogenase; LDHA: Lactate dehydrogenase, subunit A; MCT1: Monocarboxylate transporter 1; MCT4: Monocarboxylate transporter 4; HIF1 $\alpha$ : Hypoxia-inducible factor 1a; RPL19: 60S ribosomal protein L19; Lac/Pyr: Lactate-to-pyruvate ratio; ROI: Region of interest; SNR: Signal-to-noise ratio; PI-RADS: Prostate Imaging Reporting \& Data System; $\mathrm{T}_{1}$ : Spin-lattice relaxation time constant; GLC: 1,2-glycerol carbonate; ACES: N-(2-acetamido)2-aminoethanesulfonic acid; DEMA: Diethylmalonic acid; CA: Carbonic anhydrase; RMS: Root mean square; IACUC: Institutional Animal Care and Use Committee; 3D GRASE: 3D gradient-spin echo; 2D CSI: 2D chemical shift imaging; FOV: Field of view; TR: Repetition time; SLR: Shinnar-Le Roux; H\&E: Hematoxylin and eosin.

\section{Author contributions}

All authors read the manuscript and contributed edits. R. Bok and K. Liu performed mouse imaging experiments. R. Bok and L. Delos Santos performed euthanasia and tissue harvests, and they read histological slides. H. Qin, I. Lobach and N. Korn advised on imaging data interpretation and statistical analyses. R. Sriram, D. Wilson, J. Kurnanewicz, and R. Flavell conceived of study design and determined strategies for data collection, analysis, and presentation.

\section{ACKNOWLEDGMENTS}

The authors thank the past and current members of the Flavell and Kurhanewicz laboratories, especially Hsin-Yu Chen for consultation and Celine Taglang, Justin Delos Santos, Jessie Lee, Celine Baligand, Sukumar Subramaniam, and Mark VanCriekinge, for help with troubleshooting and running experiments.

\section{CONFLICTS OF INTEREST}

The authors declare no conflicts of interest.

\section{FUNDING}

J.K. acknowledges support from the National Institutes of Health (R01-CA166766) and the Department of Defense (PC140571P4). R.R.F. acknowledges support 
from the National Institutes of Health (R21-EB026012), the Department of Defense (Physician Research Training Grant PC150932), University of California Cancer Research Committee Award (CRN-19-581541), a UCSF Research Allocation Program Pilot Award, and the Prostate Cancer Foundation David Blitzer Young Investigator Award. Publication made possible in part by support from the UCSF Open Access Publishing Fund.

\section{REFERENCES}

1. Siegel RL, Miller KD, Jemal A. Cancer statistics, 2019. CA Cancer J Clin. 2019; 69:7-34. https://doi.org/10.3322/ caac.21551. [PubMed]

2. Cooperberg MR, Carroll PR, Klotz L. Active surveillance for prostate cancer: progress and promise. J Clin Oncol. 2011; 29:3669-76 https://doi.org/10.1200/ JCO.2011.34.9738. [PubMed]

3. Johnson LM, Turkbey B, Figg WD, Choyke PL. Multiparametric MRI in prostate cancer management. Nat Rev Clin Oncol. 2014; 11:346-53. https://doi.org/10.1038/ nrclinonc.2014.69. [PubMed]

4. Muller BG, Fütterer JJ, Gupta RT, Katz A, Kirkham A, Kurhanewicz J, Moul JW, Pinto PA, Rastinehad AR, Robertson C, de la Rosette J, Sanchez-Salas R, Jones JS, et al. The role of magnetic resonance imaging (MRI) in focal therapy for prostate cancer: recommendations from a consensus panel. BJU Int. 2014; 113:218-27. https://doi. org/10.1111/bju.12243. [PubMed]

5. Kitzing YX, Prando A, Varol C, Karczmar GS, Maclean F, Oto A. Benign Conditions That Mimic Prostate Carcinoma: MR Imaging Features with Histopathologic Correlation. Radiographics. 2016; 36:162-75. https://doi.org/10.1148/ rg.2016150030. [PubMed]

6. Gold SA, Hale GR, Bloom JB, Smith CP, Rayn KN, Valera V, Wood BJ, Choyke PL, Turkbey B, Pinto PA. Follow-up of negative MRI-targeted prostate biopsies: when are we missing cancer? World J Urol. 2019; 37:235-41. https://doi. org/10.1007/s00345-018-2337-0. [PubMed]

7. Tessem MB, Swanson MG, Keshari KR, Albers MJ, Joun D, Tabatabai ZL, Simko JP, Shinohara K, Nelson SJ, Vigneron DB, Gribbestad IS, Kurhanewicz J. Evaluation of lactate and alanine as metabolic biomarkers of prostate cancer using 1H HR-MAS spectroscopy of biopsy tissues. Magn Reson Med. 2008; 60:510-16. https://doi.org/10.1002/mrm.21694. [PubMed]

8. Albers MJ, Bok R, Chen AP, Cunningham CH, Zierhut ML, Zhang VY, Kohler SJ, Tropp J, Hurd RE, Yen YF, Nelson SJ, Vigneron DB, Kurhanewicz J. Hyperpolarized 13C lactate, pyruvate, and alanine: noninvasive biomarkers for prostate cancer detection and grading. Cancer Res. 2008; 68:8607-15. https://doi.org/10.1158/0008-5472.CAN-080749. [PubMed]

9. Ardenkjaer-Larsen JH, Fridlund B, Gram A, Hansson G, Hansson L, Lerche MH, Servin R, Thaning M, Golman K.
Increase in signal-to-noise ratio of $>10,000$ times in liquidstate NMR. Proc Natl Acad Sci USA. 2003; 100:10158-63. https://doi.org/10.1073/pnas.1733835100. [PubMed]

10. Nelson SJ, Kurhanewicz J, Vigneron DB, Larson PE, Harzstark AL, Ferrone M, van Criekinge M, Chang JW, Bok R, Park I, Reed G, Carvajal L, Small EJ, et al. Metabolic imaging of patients with prostate cancer using hyperpolarized $\left[1-{ }^{13} \mathrm{C}\right]$ pyruvate. Sci Transl Med. 2013; 5:198ra108-8. https://doi.org/10.1126/scitranslmed.3006070. [PubMed]

11. Wilson DM, Keshari KR, Larson PE, Chen AP, Hu S, Van Criekinge M, Bok R, Nelson SJ, Macdonald JM, Vigneron DB, Kurhanewicz J. Multi-compound polarization by DNP allows simultaneous assessment of multiple enzymatic activities in vivo. J Magn Reson. 2010; 205:141-47. https:// doi.org/10.1016/j.jmr.2010.04.012. [PubMed]

12. Keshari KR, Sriram R, Koelsch BL, Van Criekinge M, Wilson DM, Kurhanewicz J, Wang ZJ. Hyperpolarized ${ }^{13} \mathrm{C}$-pyruvate magnetic resonance reveals rapid lactate export in metastatic renal cell carcinomas. Cancer Res. 2013; 73:529-38. https://doi.org/10.1158/0008-5472.CAN12-3461. [PubMed]

13. Sriram R, Van Criekinge M, DeLos Santos J, Keshari KR, Wilson DM, Peehl D, Kurhanewicz J, Wang ZJ. Noninvasive differentiation of benign renal tumors from clear cell renal cell carcinomas using clinically translatable hyperpolarized ${ }^{13} \mathrm{C}$ pyruvate magnetic resonance. Tomography. 2016; 2:35-42. https://doi.org/10.18383/j. tom.2016.00106. [PubMed]

14. Bok R, Lee J, Sriram R, Keshari K, Sukumar S, Daneshmandi S, Korenchan DE, Flavell RR, Vigneron DB, Kurhanewicz J, Seth P. The Role of Lactate Metabolism in Prostate Cancer Progression and Metastases Revealed by Dual-Agent Hyperpolarized 13C MRSI. Cancers (Basel). 2019; 11:257-18. https://doi.org/10.3390/cancers 11020257. [PubMed]

15. Keshari KR, Sriram R, Van Criekinge M, Wilson DM, Wang ZJ, Vigneron DB, Peehl DM, Kurhanewicz J. Metabolic reprogramming and validation of hyperpolarized $13 \mathrm{C}$ lactate as a prostate cancer biomarker using a human prostate tissue slice culture bioreactor. Prostate. 2013; 73:1171-81. https://doi.org/10.1002/pros.22665. [PubMed]

16. Koelsch BL, Reed GD, Keshari KR, Chaumeil MM, Bok R, Ronen SM, Vigneron DB, Kurhanewicz J, Larson PE. Rapid in vivo apparent diffusion coefficient mapping of hyperpolarized (13) C metabolites. Magn Reson Med. 2015; 74:622-33. https://doi.org/10.1002/mrm.25422. [PubMed]

17. Wike-Hooley JL, Haveman J, Reinhold HS. The relevance of tumour $\mathrm{pH}$ to the treatment of malignant disease. Radiother Oncol. 1984; 2:343-66. https://doi.org/10.1016/ S0167-8140(84)80077-8. [PubMed]

18. Kato Y, Ozawa S, Miyamoto C, Maehata Y, Suzuki A, Maeda T, Baba Y. Acidic extracellular microenvironment and cancer. Cancer Cell Int. 2013; 13:89. https://doi. org/10.1186/1475-2867-13-89. [PubMed] 
19. Martínez-Zaguilán R, Seftor EA, Seftor RE, Chu YW, Gillies RJ, Hendrix MJ. Acidic pH enhances the invasive behavior of human melanoma cells. Clin Exp Metastasis. 1996; 14:176-86. https://doi.org/10.1007/BF00121214. [PubMed]

20. Rofstad EK, Mathiesen B, Kindem K, Galappathi K. Acidic extracellular $\mathrm{pH}$ promotes experimental metastasis of human melanoma cells in athymic nude mice. Cancer Res. 2006; 66:6699-707. https://doi.org/10.1158/0008-5472. CAN-06-0983. [PubMed]

21. Estrella V, Chen T, Lloyd M, Wojtkowiak J, Cornnell HH, Ibrahim-Hashim A, Bailey K, Balagurunathan Y, Rothberg JM, Sloane BF, Johnson J, Gatenby RA, Gillies RJ. Acidity generated by the tumor microenvironment drives local invasion. Cancer Res. 2013; 73:1524-35. https://doi. org/10.1158/0008-5472.CAN-12-2796. [PubMed]

22. Korenchan DE, Flavell RR, Baligand C, Sriram R, Neumann K, Sukumar S, VanBrocklin H, Vigneron DB, Wilson DM, Kurhanewicz J. Dynamic nuclear polarization of biocompatible (13)C-enriched carbonates for in vivo pH imaging. Chem Commun (Camb). 2016; 52:3030-33. https://doi.org/10.1039/C5CC09724J. [PubMed]

23. Ibrahim-Hashim A, Cornnell HH, Abrahams D, Lloyd M, Bui M, Gillies RJ, Gatenby RA. Systemic Buffers Inhibit Carcinogenesis in TRAMP Mice. J Urol. 2012; 188:624-31. https://doi.org/10.1016/j.juro.2012.03.113. [PubMed]

24. Zhang X, Lin Y, Gillies RJ. Tumor $\mathrm{pH}$ and its measurement. J Nucl Med. 2010; 51:1167-70. https://doi.org/10.2967/ jnumed.109.068981. [PubMed]

25. Gallagher FA, Kettunen MI, Day SE, Hu DE, ArdenkjaerLarsen JH, Zandt R, Jensen PR, Karlsson M, Golman K, Lerche $\mathrm{MH}$, Brindle KM. Magnetic resonance imaging of $\mathrm{pH}$ in vivo using hyperpolarized 13C-labelled bicarbonate. Nature. 2008; 453:940-43. https://doi.org/10.1038/ nature07017. [PubMed]

26. Flavell RR, von Morze C, Blecha JE, Korenchan DE, Van Criekinge M, Sriram R, Gordon JW, Chen HY, Subramaniam S, Bok RA, Wang ZJ, Vigneron DB, Larson $\mathrm{PE}$, et al. Application of Good's buffers to $\mathrm{pH}$ imaging using hyperpolarized (13)C MRI. Chem Commun (Camb). 2015; 51:14119-22. https://doi.org/10.1039/C5CC05348J. [PubMed]

27. Korenchan DE, Taglang C, von Morze C, Blecha JE, Gordon JW, Sriram R, Larson PE, Vigneron DB, VanBrocklin HF, Kurhanewicz J, Wilson DM, Flavell RR. Dicarboxylic acids as $\mathrm{pH}$ sensors for hyperpolarized 13C magnetic resonance spectroscopic imaging. Analyst (Lond). 2017; 142:1429-33. https://doi.org/10.1039/C7AN00076F. [PubMed]

28. Düwel S, Hundshammer C, Gersch M, Feuerecker B, Steiger K, Buck A, Walch A, Haase A, Glaser SJ, Schwaiger $\mathrm{M}$, Schilling $\mathrm{F}$. Imaging of $\mathrm{pH}$ in vivo using hyperpolarized ${ }^{13}$ C-labelled zymonic acid. Nat Commun. 2017; 8:15126. https://doi.org/10.1038/ncomms15126. [PubMed]
29. Gingrich JR, Greenberg NM. A transgenic mouse prostate cancer model. Toxicol Pathol. 1996; 24:502-504. https:// doi.org/10.1177/019262339602400414. [PubMed]

30. Chen HY, Larson PE, Bok RA, von Morze C, Sriram R, Delos Santos R, Delos Santos J, Gordon JW, Bahrami N, Ferrone M, Kurhanewicz J, Vigneron DB. Assessing Prostate Cancer Aggressiveness with Hyperpolarized Dual-Agent 3D Dynamic Imaging of Metabolism and Perfusion. Cancer Res. 2017; 77:3207-16. https://doi. org/10.1158/0008-5472.CAN-16-2083. [PubMed]

31. Gingrich JR, Barrios RJ, Foster BA, Greenberg NM. Pathologic progression of autochthonous prostate cancer in the TRAMP model. Prostate Cancer Prostatic Dis. 1999; 2:70-75. https://doi.org/10.1038/sj.pcan.4500296. [PubMed]

32. Korenchan DE, Flavell RR. Spatiotemporal pH Heterogeneity as a Promoter of Cancer Progression and Therapeutic Resistance. Cancers (Basel). 2019; 11:1026. https://doi.org/10.3390/cancers11071026. [PubMed]

33. Scholz DJ, Janich MA, Köllisch U, Schulte RF, ArdenkjaerLarsen JH, Frank A, Haase A, Schwaiger M, Menzel MI. Quantified pH imaging with hyperpolarized (13) C-bicarbonate. Magn Reson Med. 2015; 73:2274-82. https:// doi.org/10.1002/mrm.25357. [PubMed]

34. Gatenby RA, Gawlinski ET, Gmitro AF, Kaylor B, Gillies RJ. Acid-mediated tumor invasion: a multidisciplinary study. Cancer Res. 2006; 66:5216-23. https://doi. org/10.1158/0008-5472.CAN-05-4193. [PubMed]

35. Lupo JM, Chen AP, Zierhut ML, Bok RA, Cunningham $\mathrm{CH}$, Kurhanewicz J, Vigneron DB, Nelson SJ. Analysis of hyperpolarized dynamic $13 \mathrm{C}$ lactate imaging in a transgenic mouse model of prostate cancer. Magn Reson Imaging. 2010; 28:153-62. https://doi.org/10.1016/j. mri.2009.07.007. [PubMed]

36. Pinheiro C, Longatto-Filho A, Azevedo-Silva J, Casal M, Schmitt FC, Baltazar F. Role of monocarboxylate transporters in human cancers: state of the art. J Bioenerg Biomembr. 2012; 44:127-39. https://doi.org/10.1007/ s10863-012-9428-1. [PubMed]

37. Cutruzzolà F, Giardina G, Marani M, Macone A, Paiardini A, Rinaldo S, Paone A. Glucose Metabolism in the Progression of Prostate Cancer. Front Physiol. 2017; 8:97. https://doi.org/10.3389/fphys.2017.00097. [PubMed]

38. Lyssiotis CA, Kimmelman AC. Metabolic Interactions in the Tumor Microenvironment. Trends Cell Biol. 2017; 27:863-75. https://doi.org/10.1016/j.tcb.2017.06.003. [PubMed]

39. Faubert B, Li KY, Cai L, Hensley CT, Kim J, Zacharias LG, Yang C, Do QN, Doucette S, Burguete D, Li H, Huet G, Yuan Q, et al. Lactate Metabolism in Human Lung Tumors. Cell. 2017; 171:358-371.e9. https://doi.org/10.1016/j. cell.2017.09.019. [PubMed]

40. Schornack PA, Gillies RJ. Contributions of cell metabolism and $\mathrm{H}+$ diffusion to the acidic $\mathrm{pH}$ of tumors. 
Neoplasia. 2003; 5:135-45. https://doi.org/10.1016/S14765586(03)80005-2. [PubMed]

41. Provent P, Benito M, Hiba B, Farion R, López-Larrubia P, Ballesteros P, Rémy C, Segebarth C, Cerdán S, Coles JA, García-Martín ML. Serial in vivo spectroscopic nuclear magnetic resonance imaging of lactate and extracellular $\mathrm{pH}$ in rat gliomas shows redistribution of protons away from sites of glycolysis. Cancer Res. 2007; 67:7638-45. https://doi.org/10.1158/0008-5472.CAN-06-3459. [PubMed]

42. Abaza M, Luqmani YA. The influence of $\mathrm{pH}$ and hypoxia on tumor metastasis. Expert Rev Anticancer Ther. 2013; 13:1229-42. https://doi.org/10.1586/14737140.2013.8434 55. [PubMed]

43. Rosenkrantz AB, Oto A, Turkbey B, Westphalen AC. Prostate Imaging Reporting and Data System (PI-RADS), Version 2: A Critical Look. AJR Am J Roentgenol. 2016; 206:1179-83. https://doi.org/10.2214/AJR.15.15765. [PubMed]

44. Greer MD, Brown AM, Shih JH, Summers RM, Marko J, Law YM, Sankineni S, George AK, Merino MJ, Pinto PA, Choyke PL, Turkbey B. Accuracy and agreement of PIRADSv2 for prostate cancer mpMRI: A multireader study. J Magn Reson Imaging. 2017; 45:579-85. https:// doi.org/10.1002/jmri.25372. [PubMed]

45. Barentsz JO, Weinreb JC, Verma S, Thoeny HC, Tempany CM, Shtern F, Padhani AR, Margolis D, Macura KJ, Haider MA, Cornud F, Choyke PL. Synopsis of the PI-RADS v2 Guidelines for Multiparametric Prostate Magnetic Resonance Imaging and Recommendations for Use. Eur Urol. 2016; 69:41-49. https://doi.org/10.1016/j. eururo.2015.08.038. [PubMed]

46. Garcia-Reyes K, Nguyen HG, Zagoria RJ, Shinohara K, Carroll PR, Behr SC, Westphalen AC. Impact of Lesion Visibility on Transrectal Ultrasound on the Prediction of Clinically Significant Prostate Cancer (Gleason Score 3 + 4 or Greater) with Transrectal Ultrasound-Magnetic Resonance Imaging Fusion Biopsy. J Urol. 2018; 199:699705. https://doi.org/10.1016/i.juro.2017.09.075. [PubMed]

47. Borofsky S, George AK, Gaur S, Bernardo M, Greer MD, Mertan FV, Taffel M, Moreno V, Merino MJ, Wood BJ, Pinto PA, Choyke PL, Turkbey B. What Are We Missing? False-Negative Cancers at Multiparametric MR Imaging of the Prostate. Radiology. 2018; 286:186-95. https://doi. org/10.1148/radiol.2017152877. [PubMed]

48. Turkbey B, Choyke PL. Multiparametric MRI and prostate cancer diagnosis and risk stratification. Curr Opin Urol. 2012; 22:310-15. https://doi.org/10.1097/ MOU.0b013e32835481c2. [PubMed]
49. Nagarajan R, Margolis D, Raman S, Sheng K, King C, Reiter R, Thomas MA. Correlation of Gleason scores with diffusion-weighted imaging findings of prostate cancer. Adv Urol. 2012; 2012:374805. https://doi. org/10.1155/2012/374805. [PubMed]

50. Panebianco V, Barchetti F, Barentsz J, Ciardi A, Cornud F, Futterer J, Villeirs G. Pitfalls in Interpreting mp-MRI of the Prostate: A Pictorial Review with Pathologic Correlation. Insights Imaging. 2015; 6:611-30. https://doi.org/10.1007/ s13244-015-0426-9. [PubMed]

51. Fair WR, Cordonnier JJ. The $\mathrm{pH}$ of prostatic fluid: a reappraisal and therapeutic implications. J Urol. 1978; 120:695-98. https://doi.org/10.1016/S0022-5347(17)573334. [PubMed]

52. Hundshammer C, Düwel S, Ruseckas D, Topping G, Dzien P, Müller C, Feuerecker B, Hövener JB, Haase A, Schwaiger M, Glaser SJ, Schilling F. Hyperpolarized Amino Acid Derivatives as Multivalent Magnetic Resonance $\mathrm{pH}$ Sensor Molecules. Sensors (Basel). 2018; 18:600. https:// doi.org/10.3390/s18020600. [PubMed]

53. Korenchan DE, Gordon JW, Subramaniam S, Sriram R, Baligand C, VanCriekinge M, Bok R, Vigneron DB, Wilson DM, Larson PE, Kurhanewicz J, Flavell RR. Using bidirectional chemical exchange for improved hyperpolarized $\left[{ }^{13} \mathrm{C}\right]$ bicarbonate $\mathrm{pH}$ imaging. Magn Reson Med. 2019; 82:959-72. https://doi.org/10.1002/mrm.27780. [PubMed]

54. Costello LC, Franklin RB, Zou J, Feng P, Bok R, Swanson MG, Kurhanewicz J. Human prostate cancer ZIP1/zinc/ citrate genetic/metabolic relationship in the TRAMP prostate cancer animal model. Cancer Biol Ther. 2011; 12:1078-84. https://doi.org/10.4161/cbt.12.12.18367. [PubMed]

55. Oshio K, Feinberg DA. Single-shot GRASE imaging without fast gradients. Magn Reson Med. 1992; 26:355-60. https://doi.org/10.1002/mrm.1910260214. [PubMed]

56. Crane JC, Olson MP, Nelson SJ. SIVIC: Open-Source, Standards-Based Software for DICOM MR Spectroscopy Workflows. Int J Biomed Imaging. 2013; 2013:169526. https://doi.org/10.1155/2013/169526. [PubMed]

57. Holz M, Heil SR, Sacco A. Temperature-dependent self-diffusion coefficients of water and six selected molecular liquids for calibration in accurate $1 \mathrm{H}$ NMR PFG measurements. Phys Chem Chem Phys. 2000; 2:4740-42. https://doi.org/10.1039/b005319h.

58. R Core Team. R: A language and environment for statistical computing [Internet]. Vienna, Austria; 2018. Available from https://www.R-project.org/. 